8

9

0

\title{
Radial Glia cell infection by Toxoplasma gondii disrupts brain microvascular endothelial cell integrity
}

Daniel Adesse ${ }^{{ }^{*}}$, Anne Caroline Marcos ${ }^{1}$, Michele Siqueira ${ }^{2}$, Cynthia M. Cascabulho ${ }^{3}$, Mariana C. Waghabi ${ }^{4}$, Helene S. Barbosa ${ }^{1}$, Joice Stipursky ${ }^{2 *}$.

\begin{abstract}
Affiliation: 1) Laboratório de Biologia Estrutural, Instituto Oswaldo Cruz, Fiocruz; 2) Laboratório de Neurobiologia Celular, ICB, UFRJ; 3) Laboratório de Inovação em Terapias, Ensino e Bioprodutos, Instituto Oswaldo Cruz, Fiocruz; 4) Laboratório de Genômica Funcional e Bioinformática, Instituto Oswaldo Cruz, Fiocruz.
\end{abstract}

*Corresponding authors: joice@icb.ufrj.br; daniel.adesse@gmail.com

Key words: congenital toxoplasmosis, Toxoplasma gondii, $\mathrm{TORCH}$, radial glia, endothelial cells, brain development, neurogenesis, blood brain barrier.

Running Title: Toxoplasma gondii impairs neurovascular interactions

8705 Words manuscript

27 Pages

3 Figures

2 Supplementary figures 


\section{ABSTRACT (228)}

Congenital toxoplasmosis is a parasitic disease that occurs due vertical transmission of the protozoan Toxoplasma gondii (T. gondii) during pregnancy. The parasite crosses the placental barrier and reaches the developing brain, infecting progenitor, glial, neuronal and vascular cell types. Although the role of Radial glia $(R G)$ neural stem cells in the development of the brain vasculature has been recently investigated, the impact of $T$. gondii infection in these events is not yet understood. Herein, we studied the role of $T$. gondii infection on RG cell function and its interaction with endothelial cells. By infecting isolated RG cells with T. gondii tachyzoites, we observed reduced cell proliferation and neurogenesis without affecting gliogenesis levels. Conditioned medium (CM) from RG control cultures increased ZO-1 and $\beta$-catenin protein levels and organization on endothelial bEnd.3 cells membranes, which was completely impaired by CM from infected $R G$, resulting in decreased transendothelial electrical resistance (TEER). Cytokine Bead Array and ELISA assays revealed the presence of increased levels of the pro-inflammatory cytokine IL-6 and reduced levels of anti-inflammatory cytokine TGF- $\beta 1$ in CM from $T$. gondii-infected RG cells. Treatment with recombinant TGF- $\beta 1$ concomitantly with CM from infected RG cultures led to restoration of ZO-1 staining in bEnd.3 cells. Our results suggest that infection of RG cells by $T$. gondii modulate cytokine secretion, which might contribute to endothelial loss of barrier properties, thus leading to impairment of neurovascular interaction establishment. 


\section{1) INTRODUCTION (904)}

Toxoplasmosis is a parasitic disease that affects all warm-blooded animals, including humans. The disease is caused by a protozoan parasite, T. gondii and has a high global seroprevalence, estimated in approximately $1 / 3$ of the world's population (Dubey, 2010). Transmission occurs by ingestion of uncooked meat from infected animals, that contains tissue cysts, or by ingestion or inhalation of sporulated oocysts, shed with feces of infected felids. The cysts are digested by proteolytic enzymes present in the stomach and small intestine, which then release infective parasites that rapidly invade epithelial cells of the small intestine and differentiate into fast-replicating tachyzoite forms. After intense intracellular proliferation, parasites promote host cell lysis and can disseminate throughout the entire organism (reviewed in Hill and Dubey, 2016). During the acute phase, patients may present lymphadenopathy, which may be associated with fever, fatigue, muscle pain, sore throat and headaches (Montoya and Liesenfeld, 2004).

T. gondii can also be vertically transmitted during gestation, leading to Congenital Toxoplasmosis (CT), established by the capacity of the parasite to cross the placental barrier and reach the developing brain tissue, where both tachyzoites and tissue cysts can be found in the developing brain parenchyma (Ferguson et al., 2013). CT is part of the

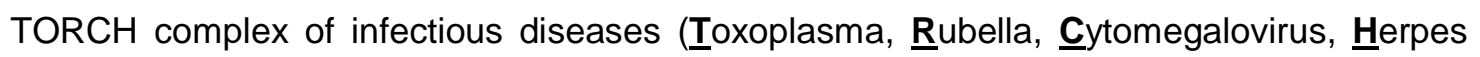
simplex 2. $\underline{\text { O }}$ stands for Others, and includes chlamydia, HIV, Coxsackievirus, Syphilis, Hepatitis B, chicken pox and Zika virus) that can be transmitted from the mother to the fetus (Neu et al., 2015; Mehrjardi, 2017). Infection with some of these pathogens can potentially lead to congenital defects including, but not limited to, microcephaly, growth and mental retardation, heart disease and hearing loss (Neu et al., 2015; Klase et al., 2016). Although transmission during the third trimester has been implicated in reduced impact on the fetus, infection during the first trimester is extremely disruptive, with severe neurological manifestations including microcephaly, cognitive/intellectual disabilities, deafness and blindness (Wallon et al., 1999). 
Deleterious effects of infection of mouse neural progenitor cells by a highly infective T. gondii strain was linked to apoptosis induction by endoplasmic reticulum stress signaling pathway activation (Wang et al., 2014). In addition, reduced neuron and astrocyte generation from the neural $\mathrm{C} 17.2$ stem cell line by disruption of the $\mathrm{Wnt} / \beta$-catenin signaling pathway have also been suggested as an underlying mechanism of $T$. gondii-induced neural pathological damage during brain development (Gan et al., 2016; Zhang et al., 2017).

$R G$ cells are the major multipotent neural stem cell population present during the embryonic cerebral cortex development period and originate most of the neuronal and glial cell types found in neural tissue, by activation of multiple signaling pathways (Gotz and Barde, 2005; Kriegstein and Alvarez-Buylla, 2009; Stipursky et al., 2012; Stipursky et al., 2014). Besides its well-known role as neural stem cells, RG have recently been demonstrated to directly control vascular development and blood brain barrier (BBB) formation in the embryonic cerebral cortex (Ma et al., 2013; Errede et al., 2014; Hirota et al., 2015; Siqueira et al., 2017).

We have previously demonstrated that the gliogenic and neurogenic potential of $R G$ cells during cerebral cortex development is controlled by TGF- $\beta 1$ signaling pathway activation, both in vitro and in vivo (Stipursky et al., 2012; Stipursky et al., 2014). Neuroepithelial and RG neural progenitors interact with immature endothelial cells, derived from the perineural vascular plexus (PNVP) that surrounds the neural tissue early during the embryonic period. Such an interaction is essential to promote invasion of endothelial cells and vascularization of the developing CNS. Endothelial cells from the PNVP invade forebrain tissue as early as E9.5 in mice and migrate towards the ventricular surface, guided by VEGF gradients secreted by neural progenitor cells (Bautch and James, 2009; Anderson et al., 2011; Liebner et al., 2011; Takahashi et al., 2015). Recently, we demonstrated that RG cells coordinate the formation of the vascular tree of the brain, by controlling angiogenesis in the developing cortex. Specifically, RG cells secrete a vast 
repertoire of pro-angiogenic factors, including TGF- $\beta 1$ and VEGF-A, that induce endothelial proangiogenic genes expression and regulate migration and blood vessel branching in the embryonic cerebral cortex (Siqueira et al., 2017).

Blood vessel development and neural cell generation in the CNS are essential steps for the establishment of the BBB. The BBB is a multicellular structure formed by capillary endothelial cells, astrocytic endfeet, pericytes and neighboring microglia and neurons, that control the transport of nutrients, oxygen and other substances, and prevent the free passage of toxic agents and pathogens (Kim et al., 2006; Anderson et al., 2011). In the adult brain, T. gondii can infect endothelial cells (Konradt et al., 2016) and, by modulation of adhesion proteins, contribute to decreased adhesion between adjacent endothelial, allowing for transmigration of inflammatory cells into the brain parenchyma (Lachenmaier et al., 2011).

Although RG physiology greatly determines the correct formation of the cerebral cortex, including its vascularization (Ma et al., 2013; Errede et al., 2014; Hirota et al., 2015; Siqueira et al., 2017), the understanding of the impact of T. gondii infection on RGendothelial interactions in the embryonic CNS has never been addressed.

Here, we investigated the role of $T$. gondii infection on RG physiology and its potential to control endothelial barrier properties establishment. We demonstrated that infection reduce the neurogenesis potential and altered the $R G$ secretome. Such altered alterations lead to important dysfunctions in microvascular brain endothelial cells, presenting reduced tight junction stability and barrier properties when incubated with a conditioned medium obtained from infected RGs.

\section{2) MATERIAL AND METHODS (1229)}

2.1) Compliance with Ethical Standards: All animal protocols were approved by the Federal University of Rio de Janeiro Animal Research Committee (CEUA 041/14). Animals 
131 were housed in a temperature-controlled room with a 12/12 $\mathrm{h}$ light/dark cycle and allowed 132 food and water ad libitum.

2.2) Toxoplasma gondii infection: Parasites from the ME49 strain were obtained from the brains of $\mathrm{C} 57 / \mathrm{bl} 6$ mice infected 45 days before isolation. Cysts were ruptured with an acid pepsin solution and free parasites were added to monolayers of Vero cells $\left(\right.$ ATCC $\left.^{\circledR} \mathrm{CCL}-81^{\mathrm{TM}}\right)$. After two weeks of culture re-infections, tachyzoites released from the supernatant were collected and centrifuged. Cell cultures were infected with the tachyzoites $300 \mu \mathrm{L}$ of DMEM-/F12/2\% B27/ Penicilin-streptocycin (Thermo) (RG cultures). Cells were washed in Ringer's solution, fresh culture media was added, and cultures were kept for additional 22 hours, when conditioned medium was collected and cells fixed for immunostaining. Mock-infected cultures (treated with fresh culture medium) were used as controls. mouse embryos was carried out as previously described by Stipursky et al. (2014). Briefly, gestational day14 Swiss mice embryos were collected and dissected for cerebral cortex separation. After dissection, tissues were dissociated in DMEM/F12 Glutamax high glucose (Thermo) medium and after cell counting, $3.10^{5}$ cells were plated in $25 \mathrm{~cm} 2$ culture flasks in neurosphere "growing media" DMEM/F12 Glutamax high glucose (Thermo) containing 0.1\% penicillin/streptomycin, 2\% B27 (Thermo), 20ng/mL EGF (epidermal growth factor, Thermo) and $20 \mathrm{ng} / \mathrm{mL}$ FGFb (basic fibroblast growth factor, R\&D Systems), for 6 days, in vitro. $2 / 3$ of the media was changed every 2 days. After this period, neurospheres were enzymatically dissociated in $0.05 \%$ Trypsin/EDTA (Thermo). After cells isolation, $2.10^{5}$ cells were plated on glass coverslips previously coated with $5 \mu \mathrm{g} / \mathrm{mL}$ laminin (Thermo) and incubated in DMEM/F12 Glutamax (high glucose) without serum and supplemented with 2\% B27, $20 \mathrm{ng} / \mathrm{mL}$ FGFb and EGF (Thermo). Twenty-four hours after plating, cells were infected with the tachyzoite forms of the T. gondii, ME49 strain as described above. After infection, cells were gently washed to remove extracellular parasites and $300 \mu \mathrm{L}$ of fresh 
159 DMEM/F12/ medium were added, followed by 22 hours of incubation. Next, non-infected 160 and infected RG cells were fixed with paraformaldehyde $4 \%$ solution in PBS (Sigma161 Aldrich) for immunocytochemistry assays. Supernatants were collected, centrifuged for 10 min at $10,000 \mathrm{rpm}(4 \stackrel{\circ}{\mathrm{C}})$ to eliminate cell debris and extracellular parasites and frozen at $80 \stackrel{\circ}{ } \mathrm{C}$ to be further used as a Conditioned Medium (CM) or for cytokine measurements.

2.4) Enzyme-Linked Immunosorbent Assay (ELISA): TGF- $\beta 1$ levels present in the conditioned medium derived from non-infected (RG-CM) and infected (Inf-RG-CM) RG cells, were measured by the Mouse TGF- $\beta 1$ ELISA DuoSet Kit (R\&D Systems) following the manufacturer's instructions.

2.5) Cytometric Bead Array (CBA): Cytokine levels were evaluated by flow cytometry in culture RG-CM and Inf-RG-CM supernatants. IL-10, IL-17, TNF, IFN- $\gamma$, IL-6, IL4 and IL-2 were detected using a Cytometric Bead Array (CBA) Th1/Th2/TH17 kit (BD), according to the manufacturer's instructions. Samples were acquired using a FACScalibur flow cytometer (BD), and the data analysis was performed using the CBA analysis FCAP software $(B D)$.

2.6) bEnd.3 cell line cultivation: A total of $6.10^{4}$ murine brain microvascular endothelial cells (bEnd.3, ATCC ${ }^{\circledR} \mathrm{CRL}-2299^{\mathrm{TM}}$ ) were plated on glass coverslips previously coated with $0.01 \%$ porcine gelatin solution (Sigma-Aldrich) in bEnd.3 medium [DMEM/F12 Glutamax high glucose (4500 mg/L) with $10 \%$ heat-inactivated Fetal Bovine Serum (Cultilab) and 1\% penicillin/streptomycin solution (Thermo)] for 14 days, with the medium changed every 2 days. After reaching confluence, cultures were treated with RG-CM, InfRG-CM, Inf-RG-CM+TGF- $\beta 1$ (10ng/Ml, R\&D Systems) or TGF- $\beta 1(10 \mathrm{ng} / \mathrm{mL})$ for 24 hours. Cultures were fixed with PFA $4 \%$ for immunocytochemistry assays. Cells were used between passages 25 to 30 .

2.7) Immunocytochemistry: Immunostaining was performed as previously described by Siqueira et al. (2017). Briefly, fixed cultures were permeabilized for 5 min with $0.05 \%$ Triton $\mathrm{x}-100$ solution in PBS and non-specific binding blocked by incubation with blocking solution containing 5\% Bovine Serum Albumin (BSA - Sigma-Aldrich)/2.5\% Normal Goat 
187 Serum (NGS)/PBS for 1 hour. Cells were incubated with primary antibodies, diluted in

188 blocking solution and maintained overnight at $4^{\circ} \mathrm{C}$. For $\mathrm{RG}$ cultures, immunostaining 189 primary antibodies were: mouse anti-Nestin (marker of neural progenitor cells, Millipore, 190 1:200); rabbit anti-BLBP (marker of radial glia cells, Chemicon, 1:500), rabbit anti-Ki67 191 (nuclear marker of mitotic cells, Abcam, 1:100), rabbit anti-GFAP (intermediary filament 192 protein specific to glial cells, Dako Cytomation, 1:500) and mouse anti- $\beta$-III-tubulin (specific 193 isoform found in immature neurons, Promega, 1:1000), and mouse anti-cleaved Caspase 3 194 (apoptosis cell marker, Abcam, 1:100). For endothelial culture immunostaining, primary 195 antibodies were: mouse anti-ZO-1 (Invitrogen, 1:300), rabbit anti- $\beta$-catenin (Sigma-Aldrich, 196 1:200). Subsequently, cells were extensively washed in PBS and incubated with secondary 197 antibodies, conjugated to AlexaFluor 488 or AlexaFluor 546 (Thermo), for $2 \mathrm{~h}$ at room temperature. Nuclei were DAPI-labeled (4', 6-Diamidino-2-phenylindole; Sigma-Aldrich). Glass coverslips were mounted in glass slides with Faramount mounting media (Dako Cytomation) and visualized under a fluorescence optical microscope Nikon TE3000 or a triplicate.

2.8) Trans-Endothelial Electrical Resistance (TEER): bEnd.3 cells were plated onto $0.01 \%$ gelatin-coated Transwell inserts (Falcon) with $3 \mu \mathrm{m}$ pores at a density of $10^{5}$ cells per insert. Cultures were maintained in bEnd. 3 medium at $37^{\circ} \mathrm{C}$ in $5 \% \mathrm{CO}_{2}$ atmosphere and resistance was measured daily using a Millicell-Electrical Resistance System (Millipore, Bedford, MA) with an adjustable electrode ("chopstick electrode^, MERSSTX03), as described by Srinivasan et al., 2015. Cells reached confluence after approximately 14 days (minimum of $60 \Omega \times \mathrm{cm}^{2}$ ), with the medium changed every 2 days. One electrode is inserted into the upper trans-well insert compartment and the other electrode to the lower compartment. Care is taken to ensure that all compartments have the same volume of medium across biological and technical replicas $(300 \mathrm{ml}$ in the upper compartment and $600 \mathrm{ml}$ in the lower). A square wave current of $12.5 \mathrm{~Hz}$ is applied to the 
215 electrodes and the resulting current is measured. To calculate TEER, the background

216 resistance reading from an empty insert was subtracted from the resistance reading for

217 each condition and the result was multiplied by 0.33 , relative to the insert area, and results

218 were expressed as $\Omega \times \mathrm{cm}^{2}$. One insert per experiment was maintained in bEnd.3 medium

219 (10\% FBS), while experimental data was obtained from cultures incubated with DMEM/F12

220 high glucose with antibiotics solution and no FBS. Cells were used for experiments when

221 TEER reached a minimum of $60 \Omega \times \mathrm{cm}^{2}$. TEER was obtained before experimental

222 procedures $(\mathrm{t}=0)$ and $24 \mathrm{~h}$ after treatments with $\mathrm{CMs}$ or infection $(\mathrm{t}=24)$. The variation index

223 for each experimental condition was calculated as $\mathrm{TEER}_{\mathrm{t}=24} / \mathrm{TEER}_{\mathrm{t}=0 \text {. }}$

2.9) Quantification and statistical analyses: Quantification analyses of cell populations (RG, neurons and astrocytes) were carried out manually using the Photoshop

226 CS6 software. The percentage of each stained cell population, in each microscopic field, 227 was calculated in relation to total DAPI stained cells numbers in the same field. bEnd.3 228 labeling intensity analysis was carried out using the ImageJ software and the TiJOR 229 analysis was performed using the TiJOR macro for ImageJ, which in an index of localization 230 of tight junction proteins in membrane-membrane contact region of adjacent cells as 231 described by Terryn et al. (2013). The GraphPad Prism 6.0 software was used for the 232 statistical analyses, obtained at http://www.graphpad.com/scientific-software/prism. 233 Statistical significance from at least 3 independent experiments was determined by 234 unpaired t-test and ANOVA for biological effects with an assumed normal distribution. P value $<0.05$ was considered statistically significant. 
3) RESULTS (767)

\section{1) T. gondii infection alters Radial Glia cell numbers and neurogenesis.}

In order to understand the effects of $T$. gondii infection on the RG differentiation potential, isolated RG cells from E14 cerebral cortex were infected with the tachyzoite forms of the parasite. We used the cells 24 hours after neurosphere dissociation and plating. At this time, Radial glia cultures are virtually pure with $96 \%$ of cells positive for blbp and $95.7 \%$ positive for nestin (92\% were blbp/nestin double positive, Stipursky J., personal communications). After 24 hours of infection with T. gondii, mock-infected (control) cells displayed typical radial bipolar morphology and expression of typical RG neural stem cells markers BLBP and Nestin, in vitro (Figure 1A). Parasites were detected in the cytoplasm of Nestin-positive cells (Supplementary Figure 1C-D). Infected cultures presented a 40\% decrease in the number of BLBP/Nestin double-labeled cells (Figure 1 A-C). This event was accompanied by a $25 \%$ decrease in proliferative RG cells double labeled for Ki67 and Nestin markers (Figure 1 D-E). In parallel, T. gondii infection also significantly decreased the numbers of early neurons (as detected by $\beta$-III-tubulin labeling) by $36 \%$ (Figure 1 G-I). However, no effect on the number of astrocytic (GFAP-positive) cells was detected in infected cultures compared to the controls (Figure $1 \mathrm{~J}-\mathbf{L}$ ). The average of total cells number of $\beta$-TubulinIII and Nestin positive cells double labeled for the apoptotic marker cleavedCaspase 3 was not affected by infection (Supplementary Figure 2A). Overall, T. gondiiinfected cultures presented a shift in the percentage of cell composition when compared to uninfected controls, with Nestin/BLBP and $\beta$-III-tubulin positive cells being directly affected, although other unidentified cell types also tended to present percentage alterations, increasing from 17\% in controls to $40 \%$ in infected cultures (Figure 1M).

\section{2) T. gondii infection affects RG potential to control endothelial barrier property.}

To investigate the potential of RG cells to control endothelial cells function and the 
266 confluence. Through immunocytochemistry analyses, we identified ZO-1 adapter tight 267 junction protein mainly distributed along cell-cell contacts in the control condition (Figure 268 2A). Treatment of endothelial cells with conditioned medium derived from uninfected RG 269 cells (RG-CM) for $24 \mathrm{~h}$ significantly increased the ZO-1 labeling intensity levels by $36 \%$ 270 (Figure 2B, D). This was concomitant with an increase in organization levels of the tight 271 junctions (TiJOR) by $90 \%$ (Figure $2 \mathrm{E}$ ). However, treatment of endothelial cells with 272 conditioned medium derived from infected RG cells (Inf-RG-CM) completely abrogated RG 273 potential to induce ZO-1 labeling intensity, by $40 \%$, when compared to control cultures, 274 although the TiJOR index did not differ from the controls (Figure 2 C, D). In summary, Inf275 RG-CM-treated presented deleterious effects on tight junction protein levels and 276 organization.

277 Additionally, a functional trans-endothelial electrical resistance (TEER) assay was 278 performed to investigate whether the structural tight junction modifications observed herein 279 were accompanied by alterations in endothelial monolayer barrier properties. Cultivation of 280 endothelial cells with RG-CM for $24 \mathrm{~h}$ increased TEER barrier properties by $22 \%$. However, 281 addition of Inf-RG-CM completely impaired RG-induced increases in barrier properties, 282 although no significant alterations were observed in cell morphology. Treatment with Inf283 RG-CM decreased TEER barrier properties by $27 \%$ when compared to the controls (Figure 2842 F).

The role of $R G$ infection on the distribution of the pro-angiogenic signaling protein $\beta$ catenin in endothelial cells was also investigated. The deleterious effect of Inf-RG-MC seen in TiJOR and TEER was also true for $\beta$-catenin protein distribution on bEnd.3 cells monolayers. In the control condition, $\beta$-catenin colocalized with ZO-1 along cell-cell contacts (Figure 2 G, J, M). The RG-CM treatment significantly increased $\beta$-catenin immunolocalization at junctional regions, which was impaired by Inf-RG-CM treatment 
3.3) T. gondii-infected RG cultures present altered cytokine secretion that 294 affects endothelial cell barrier properties.

295 To gain insight into the possible alterations induced by $T$. gondii on the RG secretory 296 protein repertoire, a CBA analysis was carried out to measure the inflammation related 297 factors IL-2, IL-4, IL-6, IL-10, IL-17, IFN- $\gamma$ and TNF- $\alpha$, followed by an ELISA analysis for 298 the neuroprotector TGF- $\beta 1$, to measure the levels of these cytokines in the RG-CM and 299 Inf-RG-CM. No detectable levels of IL-2, IL-4, IL-10, IL-17, IFN- $\gamma$ and TNF- $\alpha$, in the 300 conditioned mediums were observed. CM from infected RG cultures showed IL-6 in 301 increased concentrations $(7.4 \mathrm{pg} / \mathrm{ml})$ when compared to $\mathrm{CM}$ from control RG-CM $(0.3$ $302 \mathrm{pg} / \mathrm{ml}, \mathrm{p}<0.01$, unpaired $t$ test). TGF- $\beta 1$ levels were $40 \%$ decreased in Inf-RG-CM when 303 compared to uninfected cultures (18 versus $29 \mathrm{pg} / \mathrm{ml}, \mathrm{p}<0.05$, Unpaired Student's T test) 304 (Figure 3A).

305 Since TGF- $\beta 1$ has a crucial role on brain microvasculature, we treated bEnd.3 cells 306 with Inf-RG-CM together with recombinant TGF- $\beta 1(10 \mathrm{ng} / \mathrm{mL})$ for 24 hours and performed 307 immunocytochemistry for ZO-1. Addition of TGF- $\beta 1$ to Inf-RG-CM completely rescued the 308 ZO-1 labeling intensity to levels comparable to RG-CM condition, similarly to addition of 309 TGF- $\beta 1$ alone (Figure 3 B). 


\section{DISCUSSION (2200)}

\section{1) RG differentiation potential is impaired by T. gondii infection}

RG cells have been extensively investigated concerning several features, including neuronal migration support and multipotent neural stem cell potential in generating neurons, astrocytes, oligodendrocytes and other progenitor subtypes in the cerebral cortex (Rakic, 1999; Noctor et al., 2001; Morest and Silver, 2003; Barnabe-Heider et al., 2005; Stipursky and Gomes, 2007; Kessaris et al., 2008; Kriegstein and Alvarez-Buylla, 2009; Ortega and Alcantara, 2010; Stipursky et al., 2012; Stipursky et al., 2014). Evidence suggest that neural progenitors are directly affected by the $\mathrm{TORCH}$ complex of perinatal infectious diseases neural stem cell line (Gan et al., 2016; Wang et al., 2014; Zhang et al., 2017). However, further characterization and evaluation of the effects of $T$. gondii infection on primary RG cells isolated from embryonic cerebral cortex have not yet been addressed. The present study indicates that $T$. gondii significantly decreases the number of Nestin/BLBP positive RG cells, possibly by decreasing their proliferation. Accordingly, previous data describe that altered neural stem cell proliferation, differentiation and apoptosis can be triggered by viral infection (Gan, 2016; Souza et al., 2016). In our model, RG cells accounted for $51 \%$ of the total cell population in the control condition after a total period of $48 \mathrm{~h}$ of cultivation. Since the total number of cells and the small percentage of apoptotic RG cells were not affected by $T$. gondii infection, it is possible that global cytotoxic infection effects were not the mechanism leading to reduced numbers of, specifically, Nestin/BLBP positive RG cells. Although RG cells have been described by our group and others to differentiate into astrocytes at later stages of cortical development (Rakic, 1971; de Azevedo et al., 2005; Stipursky and Gomes, 2007; Stipursky et al., 2012; Stipursky et al., 2014), no alterations in astrocyte differentiation by $T$. gondii infection were observed. Secreted levels of IL-6 and 
340 TGF- $\beta 1$, two cytokines known to positively mediate astrocyte differentiation from neural

341 progenitor cells (Taga and Fukuda, 2005; Nakamura et al., 2005, Stipursky and Gomes, 342 2007; Stipursky et al., 2012; Stipursky et al., 2014), were altered in Inf-RG-CM. However, it 343 is possible that, in this context, altered cytokine levels might not control autocrine regulation 344 of astrocytogenesis, or that other molecular mechanisms known to modulate gliogenesis 345 are not altered in this context. On the other hand, a reduction in $\beta$-III-tubulin positive cell numbers was detected, without affecting apoptotic neuronal population, suggesting inhibition of neurogenesis. This finding is corroborated by the recent demonstration that $T$. gondii infection impairs neuron generation from C17.2 neural stem cell line in vitro (Gan et al., 2016; Zhang et al., 2017). However, it is possible that, in addition to T. gondii induced alterations of well-known molecular mechanisms that control neurogenesis during cortical development, such as Wnt/ßcat signaling (Gan et al., 2016; Zhang et al., 2017) and neuronal differentiation transcription factors, such as Fabp7/BLBP, Sox2, Tacc3 Eya1, Sox2, and Tnfrsf12a genes (Xiao et al., 2012), altered levels of IL-6, TGF- $\beta 1$ and other, still unidentified cytokines, might exert an autocrine effect on the neurogenic potential of $R G$ cells. Although T. gondii infection decreased the number of Nestin/BLBP and $\beta$-III-tubulin positive cells and did not alter GFAP cells numbers, overall cell composition percentages induced an increase in an unidentified cell population, suggesting that RG differentiation might favor the appearance of other cell types. Thus, since the literature lacks a more detailed investigation regarding the impact of congenital transmission of $T$. gondii in cerebral cortex embryonic development in vivo, it is essential to address how neurogenesis and/or gliogenesis are affected during CT in the developing brain. 
368 (Carmeliet and Jain, 2000). In the last few years, RG have been pointed out as an 369 essential cellular and molecular scaffold for blood vessel formation and vascular 370 stability acquisition during cerebral cortex development (Ma et al., 2013; Errede et al., 371 2014; Hirota et al., 2015; Siqueira et al., 2017). Herein, we demonstrate that RG-CM 372 treatment of endothelial cells greatly increases tight junction ZO-1 protein levels and 373 organization, suggesting that RG-secreted factors promote microvascular barrier 374 formation. Vascular stability and barrier properties are essential features that allow 375 the controlled transport of nutrients and other substances across the BBB (Abbott, 376 2005; Ben-Zvi et al., 2014). Several molecular mechanisms were shown to promote 377 the expression of tight junction proteins Claudin-5, Occludin and ZO-1 in endothelial 378 cells, thus leading to the formation of the BBB, including activation of the TGF- $\beta 1$ signaling pathway, PDGFR/PDGR-B interaction and Wnt/ßcatenin (Alvarez et al., 2011; Baeten and Akassoglou, 2011; Zhao et al., 2014; Zhao et al., 2015). In this context, T. gondii infection may indirectly deregulate signaling pathways critical in controlling vessel stability by (i) affecting RG potential concerning mediation of BBB formation or (ii) disrupting tight junction proteins expression and organization directly in endothelial cells. Increased BBB disruption and permeability have been recently correlated t elevated levels of the pro-inflammatory cytokine IL-6 in the cerebrospinal fluid of human adult individuals affected by neuromyelitis optica and neuropsychiatric systemic lupus erythematosus, and in a rat model of psychosocial stress induction (Uchida et al., 2017; Asano et al., 2017; Schiavone et al., 2017). BBB dysfunction in several neurodegenerative disease contexts, such as Alzheimer's, Parkinson's and Multiple sclerosis, as well as CNS ischemia and infectious diseases, being a potential neuroinflammation establishment mechanism (Kempuraj et al., 2016; Rochfort et al., 2016). Stimulation of endothelial human brain cells (HCECs) with IL-6 was shown to induce VEGF synthesis and release, promoting angiogenesis, alongside increased expression of matrix metalloproteinase 9 (MMP9) (Yao et al., 2006). Increased MMPs 
396 levels in different brain injury models were associated with degradation of the endothelial 397 basement membrane and enhanced tyrosine phosphorylation of tight junction proteins, 398 triggering protein redistribution, changes in adhesive properties between endothelial cells, and TEER reduction, resulting in increased permeability (Stamatovic et al., 2008).

Although the roles of IL-6 have been pointed as essential to endothelial function, 401 angiogenesis and blood vessel stability have been classically described as depending on 402 anti-inflammatory TGF- $\beta 1$ cytokine signaling in the embryonic and adult brain (Dohgu et al., 403 2004; Lebrin et al., 2005; Holderfield and Hughes, 2008; Arnold et al., 2014; Hellbach et al., 404 2014; Siqueira et al., 2017). TGF- $\beta 1$ is a multifunctional cytokine that controls multiple 405 physiological and pathological events, such as embryogenesis, immune response, ECM 406 synthesis, cell differentiation and cell-cycle control in several tissues (Massague, 1998; 407 Massague and Gomis, 2006). TGF- $\beta 1$ in the CNS has been reported to play a key role in 408 neuronal generation, survival and migration (Brionne et al., 2003; Miller, 2003; Esposito et al., 2005; Stipursky et al., 2012), glial differentiation (Sousa Vde et al., 2004; Romao et al., 413 that CM from infected RG cells contains lower TGF- $\beta 1$ levels compared to uninfected cells. 414 Loss of the active form of TGF- $\beta 1$ cytokine, mutation of the Tgfb1 gene or even deletion of 415 Tgfr2 or Alk5/Tgfbr1 genes in endothelial cells of the embryonic forebrain have been shown 416 to promote excessive vascular sprouting, branching and induce cerebral hemorrhage 417 (Arnold et al., 2014). Furthermore, TGF- $\beta 1$ is known to promote tight junction proteins and 418 P-glycoprotein transporter expression in brain endothelial cells (Dohgu et al., 2004), induce 419 endothelial barrier properties, such as $\gamma$-glutamyl-transferase (GGT) expression, mediated 420 by astrocyte secretion (Garcia et al., 2004), and TGF- $\beta$ signaling is involved in later stages 421 of blood vessel development, such as the induction of maturation and stability maintenance mediating the interaction between endothelial and mural cells (Lebrin et al., 2005). 
Here we demonstrated that Inf-RG-CM presented increased amounts of IL-6 and

424 significantly less TGF- $\beta 1$, compared to control RG-CM. Evidence shows that disruption of

425 endothelial interactions with neurovascular unit or low levels of TGF- $\beta 1$ leads to abnormal

426 distribution of junctional proteins and increased vascular permeability (Garcia et al., 2004;

427 Dohgu et al., 2005; Winkler et al., 2011), In the BBB, TGF- $\beta 1$ secretion by astrocytes has

428 been demonstrated as essential for maintaining brain vasculature stability and inhibiting or

429 decreasing leukocyte transmigration across the endothelium (Fabry et al., 1995; Alvarez et

430 al., 2013). Since mature BBB astrocytes are the main source of TGF- $\beta 1$, and RG cells also

431 secrete TGF- $\beta 1$, which we demonstrated as promoting RG-astrocyte differentiation

432 (Stipursky and Gomes, 2007; Stipursky et al., 2012, 2014), it is possible that, in our

433 infection model, reduced levels of RG-derived TGF- $\beta 1$, and possibly elevated levels of IL-6

434 proinflammatory cytokine, might impair endothelial ZO-1 tight junction organization and $\beta$ -

435 catenin association in adherens junctions.

$436 \quad$ By adding TGF- $\beta 1$ to the Inf-RG-CM, there was a complete rescue of endothelial ZO-

4371 protein levels, suggesting that $T$. gondii infection impairs TGF- $\beta 1$ expression/secretion, or 438 both, by RG cells.

439 In this context, alteration of RG secretome by $T$. gondii infection, may act as 440 underlying mechanisms of disruption of endothelial cell barrier properties. However, specific 441 downstream angiogenesis and vascular maturation molecular targets have not yet been 442 identified.

$443 \quad$ Herein, $\beta$-catenin has been pointed out as a potential target for RG-endothelial 444 dysfunctional interaction. The $\mathrm{Wnt} / \beta$-catenin pathway has been extensively investigated 445 and demonstrated as exherting critical roles on vascular development and maturation in the 446 developing cerebral cortex and maintenance of BBB in adult brain (Liebner et al., 2008; 447 Daneman et al., 2009; Ma et al., 2013; Engelhardt and Liebner, 2014). $\beta$-catenin, the 448 canonical downstream mediator of Wnt signaling, associates with classic cadherins in 449 adherens junctions and to a-catenin, that mediates its association with the actin 
$450 \quad$ cytoskeleton. In endothelial cells, $\beta$-catenin is constitutively bound to VE-cadherin and when

$451 \quad \beta$-catenin is free in cytoplasm, it is rapidly inactivated by phosphorylation and ubiquitination

452 by a protein complex that includes axin and adenomatous polyposis coli (APC). Upon

453 downregulation of VE-cadherin expression or Wnt signaling activation in endothelial cells,

$454 \quad \beta$-catenin translocates to the nucleus to modulate gene expression, acting as a co-

455 transcription factor together with lymphoid enhancer factor/T-cell factor (Lef/TCF), Forkhead

456 box protein $\mathrm{O}$ (FoxO1), hypoxia-inducible factor (HIF), Smads and others, mediating

457 cellular responses such as cell cycle, apoptosis, cell differentiation and cell-cell communication (Klaus and Birchmeier, 2008; Giannotta et al., 2013).

A previous report demonstrated that VE-cadherin phosphorylation prevents $\mathrm{p} 120$ and $\beta$-catenin binding, triggering destabilization of adherens junctions, maintaining cells in a mesenchymal state (Potter et al., 2005).

Endothelial cells adherens and tight junctions lay in close proximity to neighbor cells, both mediating membrane adhesion and limiting paracellular permeability. Although adherens and tight junctions are formed by distinct structural proteins, with specific binding revision Campbell et al., 2017). In fact, $\beta$-catenin/FoxO1 transcription factor complex was demonstrated to repress Claudin-5 tight junction gene expression (Taddei et al., 2008). Ma and colleagues (2013) demonstrated that Wnt/ $\beta$-catenin signaling activation can mediate RG-endothelial interaction through transcriptionally induction of MMP2/MMP9 in endothelial cells, which was correlated to decreased vessel stability and increased endothelial proliferation in the developing cerebral cortex. Accordingly, increased MMPs levels were found in astrocyte cultures (Lu and Lai, 2013) and in the sera of pregnant women infected with T. gondii (Wang and Lai, 2013), suggesting that Wnt/ $\beta$-catenin signaling may modulate 
478 junction protein levels expression and organization and/or turnover though multiple

479 mechanisms. Thus, in our context, T. gondii infection effects might exert critical function in

480 triggering endothelial junction dismantling, alongside $\beta$-catenin dissociation from cell-cell

481 contacts.

482 Together, our results suggest that $T$. gondii deregulates RG cells proliferation, neurogenesis potential and secretory profile, with decreased TGF- $\beta 1$ and, to a less extent, increase in IL-6 levels. In addition, the potential of RG cells to modulate endothelial cell function is also affected by $T$. gondii infection, resulting in deficient organization of tight junction protein ZO-1 and junction associated $\beta$-catenin, reduced TEER, leading to impaired endothelial stabilization and loss of barrier properties. In a CT context, alterations in the $R G$ cell differentiation potential and in RG-endothelial cell interactions may be critical to the reduced numbers of neurons generated during cortical development and dysfunctional BBB formation, which would directly contribute to the establishment of the microcephaly phenotype. Although RG-endothelial interactions are critical to promote vascular development and BBB formation, the specific molecular mechanisms disrupted by T. gondii infection in such interactions are not known. Thus, an improved description of the signaling pathways involved in such events might contribute to the development of therapeutic approaches to rescue or protect neural stem cells functions and vascular development, thus preventing the clinical manifestations observed in CT. facility and some reagents; Marcelo Meloni, Adiel Batista do Nascimento and Sandra Maria Maria de Oliveira Pinto (IOC, Fiocruz) for the use of their MilliCell equipment.

503 
DA performed bEnd.3 cultures, infection and TEER experiments. $\underline{\text { ACM performed }}$

bEnd.3, treatments, immunocytochemistry quantifications and radial glia

immunocytochemistry quantifications. $\underline{M S}$ performed radial glia and bEnd.3

immunocytochemistry. $\underline{\mathrm{CMC}}$ and $\underline{\mathrm{MCW}}$ performed $\mathrm{CBA}$ and ELISA cytokines analysis,

respectively. JS performed radial glia cultures, bEnd.3 immunocytochemistry, TGF- $\beta 1$

ELISA and wrote the first draft of the manuscript. $\underline{\text { HSB }}$ discussed the experimental design and some reagents. $\underline{\mathrm{DA}}$ and $\underline{\mathrm{JS}}$ equally contributed in the design of most of the experiments. All authors contributed to manuscript revision, read and approved the submitted version.

\section{7) REFERENCES}

Abbott, N.J. (2005). Dynamics of CNS barriers: evolution, differentiation, and modulation. Cell Mol Neurobiol 25(1), 5-23.

Alvarez, J.I., Dodelet-Devillers, A., Kebir, H., Ifergan, I., Fabre, P.J., Terouz, S., et al. (2011). The Hedgehog pathway promotes blood-brain barrier integrity and CNS immune quiescence. Science 334(6063), 1727-1731. doi: 10.1126/science.1206936.

Alvarez, J.I., Katayama, T., and Prat, A. (2013). Glial influence on the blood brain barrier. Glia 61(12), 1939-1958. doi: 10.1002/glia.22575.

Anderson, K.D., Pan, L., Yang, X.M., Hughes, V.C., Walls, J.R., Dominguez, M.G., et al. (2011). Angiogenic sprouting into neural tissue requires Gpr124, an orphan $G$ protein-coupled receptor. Proc Natl Acad Sci U S A 108(7), 2807-2812. doi: 10.1073/pnas.1019761108.

Arnold, T.D., Niaudet, C., Pang, M.F., Siegenthaler, J., Gaengel, K., Jung, B., et al. (2014). Excessive vascular sprouting underlies cerebral hemorrhage in mice lacking alphaVbeta8-TGFbeta signaling in the brain. Development 141(23), 4489-4499. doi: 10.1242/dev.107193.

Asano, T., Ito, H., Kariya, Y., Hoshi, K., Yoshihara, A., Ugawa, Y., et al. (2017). Evaluation of blood-brain barrier function by quotient alpha2 macroglobulin and its relationship with interleukin-6 and complement component 3 levels in neuropsychiatric systemic lupus erythematosus. PLoS One 12(10), e0186414. doi: 10.1371/journal.pone.0186414.

Baeten, K.M., and Akassoglou, K. (2011). Extracellular matrix and matrix receptors in blood-brain barrier formation and stroke. Dev Neurobiol 71(11), 1018-1039. doi: 10.1002/dneu.20954.

Barnabe-Heider, F., Wasylnka, J.A., Fernandes, K.J., Porsche, C., Sendtner, M., Kaplan, D.R., et al. (2005). Evidence that embryonic neurons regulate the onset of cortical gliogenesis via cardiotrophin-1. Neuron 48(2), 253-265. doi: 10.1016/j.neuron.2005.08.037.

Bautch, V.L., and James, J.M. (2009). Neurovascular development: The beginning of a beautiful friendship. Cell Adh Migr 3(2), 199-204. 
546

Ben-Zvi, A., Lacoste, B., Kur, E., Andreone, B.J., Mayshar, Y., Yan, H., et al. (2014). Mfsd2a is critical for the formation and function of the blood-brain barrier. Nature 509(7501), 507-511. doi: 10.1038/nature13324.

Briceño, M.P., Nascimento, L.A., Nogueira, N.P., Barenco, P.V., Ferro, E.A., Rezende-Oliveira, K., et al. (2016). Toxoplasma gondii Infection Promotes Epithelial Barrier Dysfunction of Caco-2 Cells. J Histochem Cytochem 64(8), 459-469. doi: 10.1369/0022155416656349.

Brionne, T.C., Tesseur, I., Masliah, E., and Wyss-Coray, T. (2003). Loss of TGFbeta 1 leads to increased neuronal cell death and microgliosis in mouse brain. Neuron 40(6), 1133-1145.

Campbell, H.K., Maiers, J.L., and DeMali, K.A. (2017). Interplay between tight junctions \& adherens junctions. Exp Cell Res 358(1), 39-44. doi: 10.1016/j.yexcr.2017.03.061.

Carmeliet, P., and Jain, R.K. (2000). Angiogenesis in cancer and other diseases. Nature 407(6801), 249-257. doi: 10.1038/35025220.

Daneman, R., Agalliu, D., Zhou, L., Kuhnert, F., Kuo, C.J., and Barres, B.A. (2009). Wnt/beta-catenin signaling is required for CNS, but not non-CNS, angiogenesis. Proc Natl Acad Sci U S A 106(2), 641-646. doi: 10.1073/pnas.0805165106.

Derada Troletti, C., de Goede, P., Kamermans, A., and de Vries, H.E. (2016). Molecular alterations of the blood-brain barrier under inflammatory conditions: The role of endothelial to mesenchymal transition. Biochim Biophys Acta 1862(3), 452460. doi: 10.1016/j.bbadis.2015.10.010.

Diniz, L.P., Almeida, J.C., Tortelli, V., Vargas Lopes, C., Setti-Perdigao, P., Stipursky, J., et al. (2012). Astrocyte-induced synaptogenesis is mediated by transforming growth factor beta signaling through modulation of $\mathrm{D}$-serine levels in cerebral cortex neurons. J Biol Chem 287(49), 41432-41445. doi: 10.1074/jbc.M112.380824.

Diniz, L.P., Tortelli, V., Garcia, M.N., Araujo, A.P., Melo, H.M., Silva, G.S., et al. (2014). Astrocyte transforming growth factor beta 1 promotes inhibitory synapse formation via CaM kinase II signaling. Glia 62(12), 1917-1931. doi: 10.1002/glia.22713.

Dohgu, S., Takata, F., Yamauchi, A., Nakagawa, S., Egawa, T., Naito, M., et al. (2005). Brain pericytes contribute to the induction and up-regulation of blood-brain barrier functions through transforming growth factor-beta production. Brain Res 1038(2), 208-215. doi: 10.1016/j.brainres.2005.01.027.

Dohgu, S., Yamauchi, A., Takata, F., Naito, M., Tsuruo, T., Higuchi, S., et al. (2004). Transforming growth factor-beta1 upregulates the tight junction and P-glycoprotein of brain microvascular endothelial cells. Cell Mol Neurobiol 24(3), 491-497.

Engelhardt, B., and Liebner, S. (2014). Novel insights into the development and maintenance of the blood-brain barrier. Cell Tissue Res 355(3), 687-699. doi: 10.1007/s00441-014-1811-2.

Errede, M., Girolamo, F., Rizzi, M., Bertossi, M., Roncali, L., and Virgintino, D. (2014). The contribution of CXCL12-expressing radial glia cells to neuro-vascular patterning during human cerebral cortex development. Front Neurosci 8, 324. doi: 10.3389/fnins.2014.00324.

Esposito, M.S., Piatti, V.C., Laplagne, D.A., Morgenstern, N.A., Ferrari, C.C., Pitossi, F.J., et al. (2005). Neuronal differentiation in the adult hippocampus recapitulates embryonic development. J Neurosci 25(44), 10074-10086. doi: 10.1523/JNEUROSCI.3114-05.2005.

Fabry, Z., Topham, D.J., Fee, D., Herlein, J., Carlino, J.A., Hart, M.N., et al. (1995). TGF-beta 2 decreases migration of lymphocytes in vitro and homing of cells into the central nervous system in vivo. J Immunol 155(1), 325-332.

Ferguson, D.J., Bowker, C., Jeffery, K.J., Chamberlain, P., and Squier, W. (2013). Congenital toxoplasmosis: continued parasite proliferation in the fetal brain despite maternal immunological control in other tissues. Clin Infect Dis 56(2), 204-208. doi: $10.1093 / \mathrm{cid} / \mathrm{cis} 882$. 
Gan, X., Zhang, X., Cheng, Z., Chen, L., Ding, X., Du, J., et al. (2016). Toxoplasma gondii inhibits differentiation of C17.2 neural stem cells through Wnt/beta-catenin signaling pathway. Biochem Biophys Res Commun 473(1), 187-193. doi: 10.1016/j.bbrc.2016.03.076.

Garcia, C.M., Darland, D.C., Massingham, L.J., and D'Amore, P.A. (2004). Endothelial cell-astrocyte interactions and TGF beta are required for induction of blood-neural barrier properties. Brain Res Dev Brain Res 152(1), 25-38. doi: 10.1016/j.devbrainres.2004.05.008.

Giannotta, M., Trani, M., and Dejana, E. (2013). VE-cadherin and endothelial adherens junctions: active guardians of vascular integrity. Dev Cell 26(5), 441-454. doi: 10.1016/j.devcel.2013.08.020.

Gotz, M., and Barde, Y.A. (2005). Radial glial cells defined and major intermediates between embryonic stem cells and CNS neurons. Neuron 46(3), 369-372. doi: 10.1016/j.neuron.2005.04.012.

Goumans, M.J., Lebrin, F., and Valdimarsdottir, G. (2003). Controlling the angiogenic switch: a balance between two distinct TGF-b receptor signaling pathways. Trends Cardiovasc Med 13(7), 301-307.

Hellbach, N., Weise, S.C., Vezzali, R., Wahane, S.D., Heidrich, S., Roidl, D., et al. (2014). Neural deletion of Tgfbr2 impairs angiogenesis through an altered secretome. Hum Mol Genet 23(23), 6177-6190. doi: 10.1093/hmg/ddu338.

Hirota, S., Clements, T.P., Tang, L.K., Morales, J.E., Lee, H.S., Oh, S.P., et al. (2015). Neuropilin 1 balances beta8 integrin-activated TGFbeta signaling to control sprouting angiogenesis in the brain. Development 142(24), 4363-4373. doi: 10.1242/dev.113746.

Holderfield, M.T., and Hughes, C.C. (2008). Crosstalk between vascular endothelial growth factor, notch, and transforming growth factor-beta in vascular morphogenesis. Circ Res 102(6), 637-652. doi: 10.1161/CIRCRESAHA.107.167171.

Kempuraj, D., Thangavel, R., Natteru, P.A., Selvakumar, G.P., Saeed, D., Zahoor, H., Zaheer, S., lyer, SS. and Zaheer A. (2016). Neuroinflammation Induces Neurodegeneration. J Neurol Neurosurg Spine. 1(1). pii: 1003.

Kessaris, N., Pringle, N., and Richardson, W.D. (2008). Specification of CNS glia from neural stem cells in the embryonic neuroepithelium. Philos Trans $R$ Soc Lond $B$ Biol Sci 363(1489), 71-85. doi: 10.1098/rstb.2006.2013.

Kim, J.H., Park, J.A., Lee, S.W., Kim, W.J., Yu, Y.S., and Kim, K.W. (2006). Bloodneural barrier: intercellular communication at glio-vascular interface. $J$ Biochem Mol Biol 39(4), 339-345.

Klaus, A., and Birchmeier, W. (2009). Developmental signaling in myocardial progenitor cells: a comprehensive view of Bmp- and Wnt/beta-catenin signaling. Pediatr Cardiol 30(5), 609-616. doi: 10.1007/s00246-008-9352-7.

Konradt, C., Ueno, N., Christian, D.A., Delong, J.H., Pritchard, G.H., Herz, J., et al. (2016). Endothelial cells are a replicative niche for entry of Toxoplasma gondii to the central nervous system. Nat Microbiol 1, 16001. doi: 10.1038/nmicrobiol.2016.1.

Kriegstein, A., and Alvarez-Buylla, A. (2009). The glial nature of embryonic and adult neural stem cells. Annu Rev Neurosci 32, 149-184. doi: 10.1146/annurev.neuro.051508.135600.

Lachenmaier, S.M., Deli, M.A., Meissner, M., and Liesenfeld, O. (2011). Intracellular transport of Toxoplasma gondii through the blood-brain barrier. $J$ Neuroimmunol 232(1-2), 119-130. doi: 10.1016/j.jneuroim.2010.10.029.

Lebrin, F., Deckers, M., Bertolino, P., and Ten Dijke, P. (2005). TGF-beta receptor function in the endothelium. Cardiovasc Res 65(3), 599-608. doi: 10.1016/j.cardiores.2004.10.036.

Liebner, S., Corada, M., Bangsow, T., Babbage, J., Taddei, A., Czupalla, C.J., et al. (2008). Wnt/beta-catenin signaling controls development of the blood-brain barrier. $J$ Cell Biol 183(3), 409-417. doi: 10.1083/jcb.200806024. 
656

657

658

659

660

661

662

663

664

665

666

667

668

669

670

671

672

673

674

675

676

677

678

679

680

681

682

683

684

685

686

687

688

689

690

691

692

693

694

695

696

697

698

699

700

701

702

703

704

705

706

707

708

709

710
Liebner, S., Czupalla, C.J., and Wolburg, H. (2011). Current concepts of blood-brain barrier development. Int J Dev Biol 55(4-5), 467-476. doi: 10.1387/ijdb.103224sl.

Lu, C.Y., and Lai, S.C. (2013). Induction of matrix metalloproteinase-2 and -9 via Erk1/2-NF-kappaB pathway in human astroglia infected with Toxoplasma gondii. Acta Trop 127(1), 14-20. doi: 10.1016/j.actatropica.2013.03.004.

Ma, S., Kwon, H.J., Johng, H., Zang, K., and Huang, Z. (2013). Radial glial neural progenitors regulate nascent brain vascular network stabilization via inhibition of Wnt signaling. PLoS Biol 11(1), e1001469. doi: 10.1371/journal.pbio.1001469.

Massague, J. (1998). TGF-beta signal transduction. Annu Rev Biochem 67, 753791. doi: 10.1146/annurev.biochem.67.1.753.

Massague, J., and Gomis, R.R. (2006). The logic of TGFbeta signaling. FEBS Lett 580(12), 2811-2820. doi: 10.1016/j.febslet.2006.04.033.

Medici, D., Hay, E.D., and Goodenough, D.A. (2006). Cooperation between snail and LEF-1 transcription factors is essential for TGF-beta1-induced epithelialmesenchymal transition. Mol Biol Cell 17(4), 1871-1879. doi: 10.1091/mbc.E05-080767.

Miller, M.W. (2003). Expression of transforming growth factor-beta in developing rat cerebral cortex: effects of prenatal exposure to ethanol. J Comp Neurol 460(3), 410424. doi: 10.1002/cne.10658.

Montoya, J.G., and Liesenfeld, O. (2004). Toxoplasmosis. Lancet 363(9425), 19651976. doi: 10.1016/S0140-6736(04)16412-X.

Morest, D.K., and Silver, J. (2003). Precursors of neurons, neuroglia, and ependymal cells in the CNS: what are they? Where are they from? How do they get where they are going? Glia 43(1), 6-18. doi: 10.1002/glia.10238.

Nakamura, M., Okada, S., Toyama, Y., and Okano, H. (2005). Role of IL-6 in spinal cord injury in a mouse model. Clin Rev Allergy Immunol 28(3), 197-204. doi: 10.1385/CRIAl:28:3:197.

Neu, N., Duchon, J., and Zachariah, P. (2015). TORCH infections. Clin Perinatol 42(1), 77-103, viii. doi: 10.1016/j.clp.2014.11.001.

Noctor, S.C., Flint, A.C., Weissman, T.A., Dammerman, R.S., and Kriegstein, A.R. (2001). Neurons derived from radial glial cells establish radial units in neocortex. Nature 409(6821), 714-720. doi: 10.1038/35055553.

Nogueira, A.R., Leve, F., Morgado-Diaz, J., Tedesco, R.C., and Pereira, M.C. (2016). Effect of Toxoplasma gondii infection on the junctional complex of retinal pigment epithelial cells. Parasitology 143(5), 568-575. doi: 10.1017/S0031182015001973.

Ortega, J.A., and Alcantara, S. (2010). BDNF/MAPK/ERK-induced BMP7 expression in the developing cerebral cortex induces premature radial glia differentiation and impairs neuronal migration. Cereb Cortex 20(9), 2132-2144. doi: 10.1093/cercor/bhp275.

Pepper, M.S. (1997). Transforming growth factor-beta: vasculogenesis, angiogenesis, and vessel wall integrity. Cytokine Growth Factor Rev 8(1), 21-43.

Potter, M.D., Barbero, S., and Cheresh, D.A. (2005). Tyrosine phosphorylation of VE-cadherin prevents binding of p120- and beta-catenin and maintains the cellular mesenchymal state. J Biol Chem 280(36), 31906-31912. doi: 10.1074/jbc.M505568200.

Rakic, P. (1971). Neuron-glia relationship during granule cell migration in developing cerebellar cortex. A Golgi and electronmicroscopic study in Macacus Rhesus. J Comp Neurol 141(3), 283-312. doi: 10.1002/cne.901410303.

Rakic, P. (1999). Neurobiology. Discriminating migrations. Nature 400(6742), 315316. doi: $10.1038 / 22427$.

Rochfort, K.D., Collins, L.E., McLoughlin, A., and Cummins, P.M. (2016). Tumour necrosis factor-alpha-mediated disruption of cerebrovascular endothelial barrier integrity in vitro involves the production of proinflammatory interleukin-6. $J$ Neurochem 136(3), 564-572. doi: 10.1111/jnc.13408. 
Romao, L.F., Sousa Vde, O., Neto, V.M., and Gomes, F.C. (2008). Glutamate activates GFAP gene promoter from cultured astrocytes through TGF-beta1 pathways. J Neurochem 106(2), 746-756. doi: 10.1111/j.1471-4159.2008.05428.x.

Schiavone, S., Mhillaj, E., Neri, M., Morgese, M.G., Tucci, P., Bove, M., et al. (2017). Early Loss of Blood-Brain Barrier Integrity Precedes NOX2 Elevation in the Prefrontal Cortex of an Animal Model of Psychosis. Mol Neurobiol 54(3), 2031-2044. doi: 10.1007/s12035-016-9791-8.

Siqueira, M., Francis, D., Gisbert, D., Gomes, F.C.A., and Stipursky, J. (2017). Radial Glia Cells Control Angiogenesis in the Developing Cerebral Cortex Through TGF-beta1 Signaling. Mol Neurobiol. doi: 10.1007/s12035-017-0557-8.

Song, H.B., Jun, H.O., Kim, J.H., Lee, Y.H., Choi, M.H., and Kim, J.H. (2017). Disruption of outer blood-retinal barrier by Toxoplasma gondii-infected monocytes is mediated by paracrinely activated FAK signaling. PLoS One 12(4), e0175159. doi: 10.1371/journal.pone.0175159.

Sousa Vde, O., Romao, L., Neto, V.M., and Gomes, F.C. (2004). Glial fibrillary acidic protein gene promoter is differently modulated by transforming growth factorbeta 1 in astrocytes from distinct brain regions. Eur J Neurosci 19(7), 1721-1730. doi: 10.1111/j.1460-9568.2004.03249.x.

Souza, B.S., Sampaio, G.L., Pereira, C.S., Campos, G.S., Sardi, S.I., Freitas, L.A., et al. (2016). Zika virus infection induces mitosis abnormalities and apoptotic cell death of human neural progenitor cells. Sci Rep 6, 39775. doi: 10.1038/srep39775.

Stamatovic, S.M., Keep, R.F., and Andjelkovic, A.V. (2008). Brain endothelial cellcell junctions: how to "open" the blood brain barrier. Curr Neuropharmacol 6(3), 179192. doi: $10.2174 / 157015908785777210$.

Stipursky, J., Francis, D., Dezonne, R.S., Bergamo de Araujo, A.P., Souza, L., Moraes, C.A., et al. (2014). TGF-beta1 promotes cerebral cortex radial glia-astrocyte differentiation in vivo. Front Cell Neurosci 8, 393. doi: 10.3389/fncel.2014.00393.

Stipursky, J., Francis, D., and Gomes, F.C. (2012). Activation of MAPK/PI3K/SMAD pathways by TGF-beta(1) controls differentiation of radial glia into astrocytes in vitro. Dev Neurosci 34(1), 68-81. doi: 10.1159/000338108.

Stipursky, J., and Gomes, F.C. (2007). TGF-beta1/SMAD signaling induces astrocyte fate commitment in vitro: implications for radial glia development. Glia 55(10), 1023-1033. doi: 10.1002/glia.20522.

Taddei, A., Giampietro, C., Conti, A., Orsenigo, F., Breviario, F., Pirazzoli, V., et al. (2008). Endothelial adherens junctions control tight junctions by VE-cadherinmediated upregulation of claudin-5. Nat Cell Biol 10(8), 923-934. doi: 10.1038/ncb1752.

Taga, T., and Fukuda, S. (2005). Role of IL-6 in the neural stem cell differentiation. Clin Rev Allergy Immunol 28(3), 249-256. doi: 10.1385/CRIAI:28:3:249.

Takahashi, T., Takase, Y., Yoshino, T., Saito, D., Tadokoro, R., and Takahashi, Y. (2015). Angiogenesis in the developing spinal cord: blood vessel exclusion from neural progenitor region is mediated by VEGF and its antagonists. PLoS One 10(1), e0116119. doi: 10.1371/journal.pone.0116119.

Uchida, T., Mori, M., Uzawa, A., Masuda, H., Muto, M., Ohtani, R., et al. (2017). Increased cerebrospinal fluid metalloproteinase-2 and interleukin-6 are associated with albumin quotient in neuromyelitis optica: Their possible role on blood-brain barrier disruption. Mult Scler 23(8), 1072-1084. doi: 10.1177/1352458516672015.

Wallon, M., Liou, C., Garner, P., and Peyron, F. (1999). Congenital toxoplasmosis: systematic review of evidence of efficacy of treatment in pregnancy. BMJ 318(7197), 1511-1514.

Wang, M.F., and Lai, S.C. (2013). Fibronectin degradation by MMP-2/MMP-9 in the serum of pregnant women and umbilical cord with Toxoplasma gondii infection. $J$ Obstet Gynaecol 33(4), 370-374. doi: 10.3109/01443615.2013.769501.

Wang, T., Zhou, J., Gan, X., Wang, H., Ding, X., Chen, L., et al. (2014). Toxoplasma gondii induce apoptosis of neural stem cells via endoplasmic reticulum stress pathway. Parasitology 141(7), 988-995. doi: 10.1017/S0031182014000183. 
Winkler, E.A., Bell, R.D., and Zlokovic, B.V. (2011). Central nervous system pericytes in health and disease. Nat Neurosci 14(11), 1398-1405. doi: 10.1038/nn.2946.

Wylezinski, L.S., and Hawiger, J. (2016). Interleukin 2 Activates Brain Microvascular Endothelial Cells Resulting in Destabilization of Adherens Junctions. J Biol Chem 291(44), 22913-22923. doi: 10.1074/jbc.M116.729038.

Xiao, J., Kannan, G., Jones-Brando, L., Brannock, C., Krasnova, I.N., Cadet, J.L., et al. (2012). Sex-specific changes in gene expression and behavior induced by chronic Toxoplasma infection in mice. Neuroscience 206, 39-48. doi: 10.1016/j.neuroscience.2011.12.051.

Yao, J.S., Zhai, W., Young, W.L., and Yang, G.Y. (2006). Interleukin-6 triggers human cerebral endothelial cells proliferation and migration: the role for KDR and MMP-9. Biochem Biophys Res Commun 342(4), 1396-1404. doi: 10.1016/j.bbrc.2006.02.100.

Zhang, X., Su, R., Cheng, Z., Zhu, W., Li, Y., Wang, Y., et al. (2017). A mechanistic study of Toxoplasma gondii ROP18 inhibiting differentiation of C17.2 neural stem cells. Parasit Vectors 10(1), 585. doi: 10.1186/s13071-017-2529-2.

Zhao, Z., Nelson, A.R., Betsholtz, C., and Zlokovic, B.V. (2015). Establishment and Dysfunction of the Blood-Brain Barrier. Cell 163(5), 1064-1078. doi: 10.1016/j.cell.2015.10.067.

\section{FIGURES LEGENDS}

Figure 1. T. gondii infection decreases Radial glia cell proliferation and neurogenic potential.

Infection of RG cells cultures with $T$. gondii tachyzoites for $24 \mathrm{~h}$ significantly decreased the number of Nestin/BLBP double labeled cells number, compared with control (A-C) which was accompanied by reduced numbers of proliferative Ki67/Nestin positive cells compared with control uninfected cells (D-F). A significant decrease in generation of $\beta$-III-tubulin positive neuron numbers was induced by $T$. gondii infection, when compared with control (G-I). RG differentiation into GFAP positive astrocytes was not affected by $T$. gondii infection when compared to controls (J-L). T. gondii infection induced significant changes in the percentage of cell composition in RG cultures compared to controls (M). ${ }^{*} \mathrm{P}=0.0423,{ }^{* *} \mathrm{P}=0.0019,{ }^{* * *} \mathrm{P}=0.0001$ versus controls, unpaired $t$ test.

Figure 2. Conditioned medium from T. gondii-infected Radial glia decreases ZO$1 / \beta$-catenin proteins organization and impairs barrier properties of brain 
804 microvascular endothelial cells. Murine brain endothelial cells (bEnd.3) were incubated

805 for $24 \mathrm{~h}$ with cultivation medium (Control), conditioned medium derived from uninfected RG

806 cultures (RG-CM) or conditioned medium derived from T. gondii-infected RG cultures (Inf-

807 RG-CM). ZO-1 tight junction adapter protein was found mainly distributed along adjacent cell membranes of confluent control cultures (A). Addition of RG-CM to endothelial monolayers significantly increased the levels of ZO-1 proteins on cells surfaces $(B, E)$. bEnd.3 cells incubated with Inf-RG-CM (C, E) presented reduced levels of ZO-1 immunoreactivity, when compared with controls (A-E). Tight junction organization index in cell-cell contact regions (TiJOR) was also increased by addition RG-CM, wheb compared resistance on bEnd. 3 cells bellow control levels $(G)$. In Control cultures $\beta$-catenin was found associated with cell-cell junctional contacts, similar to ZO-1 tight junction distribution $(\mathrm{H}, \mathrm{K}$, $\mathrm{N})$. Addition of RG-CM to endothelial monolayers enhanced $\beta$-catenin immunoreactivity and similar to ZO-1 protein on cells contacts regions (I, L, O). bEnd.3 cells incubated with InfRG-CM presented reduced immunoreactivity for $\beta$-catenin similar to ZO-1, concomitant with junctions disorganization ( $J, M, P)$ when compared with controls (A-C). $\beta$-catenin distribution in infected cells were mainly displaced to intracellular parasites ${ }^{*} P=0.03$, glia cells. Conditioned medium from uninfected RG cultures (RG-CM) and from cultures infected with T. gondii tachyzoites for $24 \mathrm{~h}$ (Inf-RG-CM), were subjected to Cytokine Bead Array (CBA) and ELISA assays to measure the levels of pro and anti-inflammatory secreted cytokines. CBA detected augmented levels of IL-6 and ELISA revealed decreased TGF- $\beta 1$ 
832 levels (A) in Inf-RG-CM, compared with RG-CM. Addition of TGF- $\beta 1(19=0 \mathrm{ng} / \mathrm{mL})$ to Inf-

833 RG-CM significantly rescued the levels of ZO-1 labeling intensity, similar to addition of TGF-

$834 \quad \beta 1$ alone to bEnd.3 cells, when compared to RG-CM. ${ }^{* *} p=0.0001,{ }^{*} p=0.036$, one-way

835 ANOVA with Bonferroni post-test.

836

Supplementary figure 1 . Identification of $T$. gondii tachyzoites in infected cells.

RG cultures were infected with $T$. gondii tachyzoites for $24 \mathrm{~h}$ and labelled with DAPI to identify host cell nucleus and parasite DNA (blue). Uninfected RG cultures labeled with DAPI and Nestin (red) (A, B). Infected RG cells showing host and tachyzoites DNA in the cytoplasm (C, D, arrows), high magnification of tachyzoites in infected cells ( $\left.D^{\prime}, D^{\prime \prime}\right)$.

\section{Supplementary figure 2. T. gondii infection does not affect RG and neuronal cell}

death. RG cultures were infected with $T$. gondii tachyzoites for $2 \mathrm{~h}$ and and labelled with neuronal marker (bTubulin), RG marker (Nestin) and apoptotic cell marker (cleavedCaspase 3), No statistic differences in the percentage of $\beta$-tubulinllI/Caspase3 $(A, C)$ and Nestin/Caspase3 (B, D) double positive cells were observed. Quantification of total DAPIlabeled nucleus per microscopical field in uninfected and infected RG cultures revealed no significant difference in total cells number in both conditions $(E) . P>0.05$, unpaired $t$-test. 
bioRxiv preprint doi: https://doi.org/10.1101/378588; this version posted July 27,2018 . The copyright holder for this preprint (which was not certified by peer review) is the author/funder, who has granted bioRxiv a license to display the preprint in perpetuity. It is made available under aCC-BY-NC-ND 4.0 International license.

862

863

864

865

866

867

868

869

Figure 1.
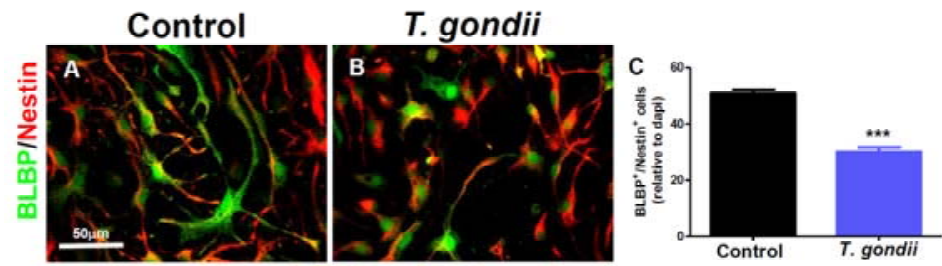

M
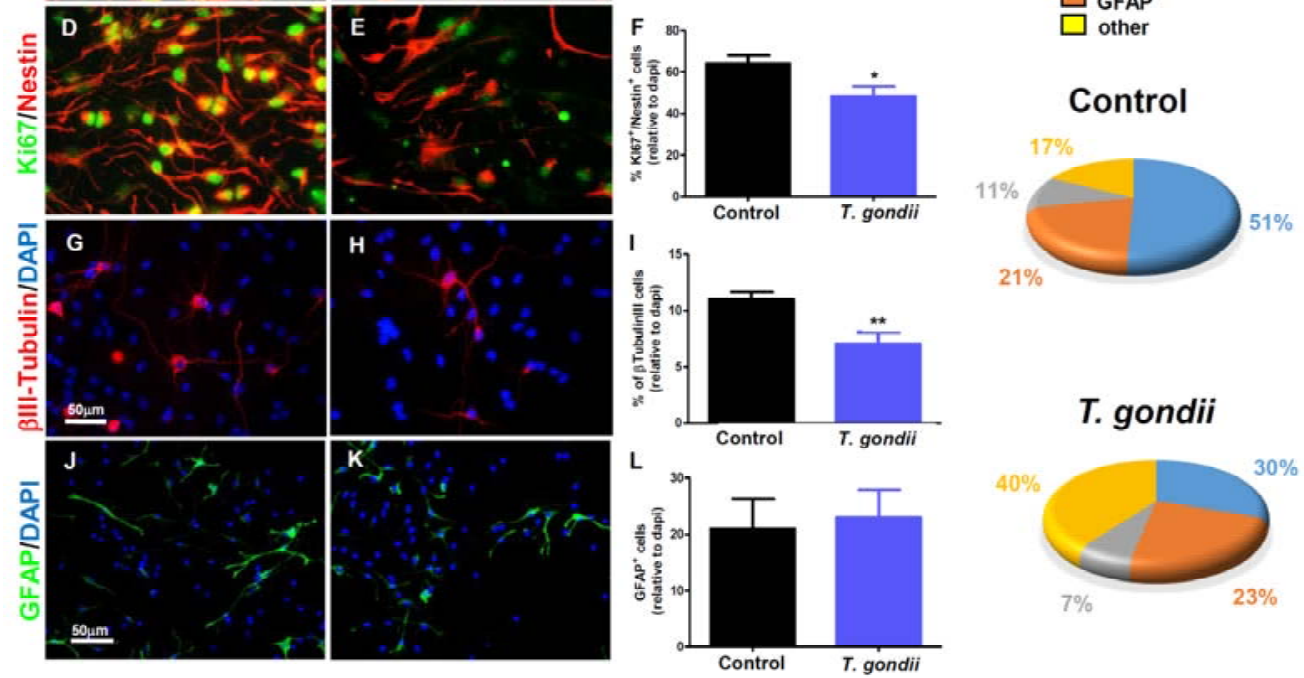

\section{T. gondii}

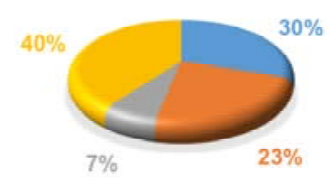

870

871 
bioRxiv preprint doi: https://doi.org/10.1101/378588; this version posted July 27,2018 . The copyright holder for this preprint (which was not certified by peer review) is the author/funder, who has granted bioRxiv a license to display the preprint in perpetuity. It is made available under aCC-BY-NC-ND 4.0 International license.

\section{6}

877

878

879

880

881

882

883

884 
Figure 2.
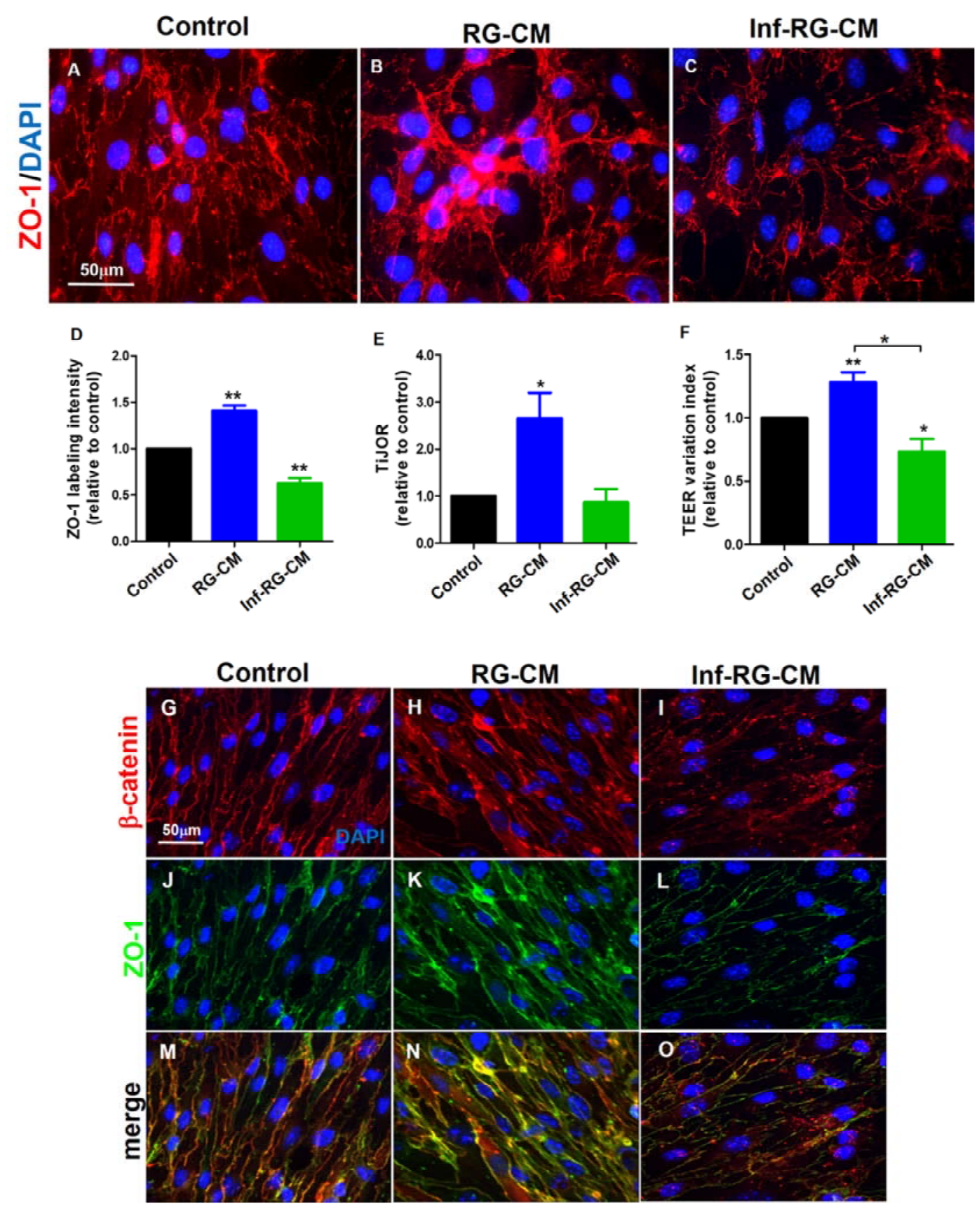


\section{Figure 3.}

A

\begin{tabular}{|c|c|c|}
\hline \multicolumn{3}{|c|}{ Cytokine levels (pg/mL) } \\
\hline & Control & T. gondii \\
\hline IL-2 & - & - \\
\hline IL-4 & - & - \\
\hline IL-6 & 0,3 & 7,4 \\
\hline IL-10 & - & - \\
\hline IL-17 & - & - \\
\hline INF- $\gamma$ & - & - \\
\hline TGF- $\beta 1$ & 29,0 & 18,0 \\
\hline TNF- $\alpha$ & - & - \\
\hline
\end{tabular}

B

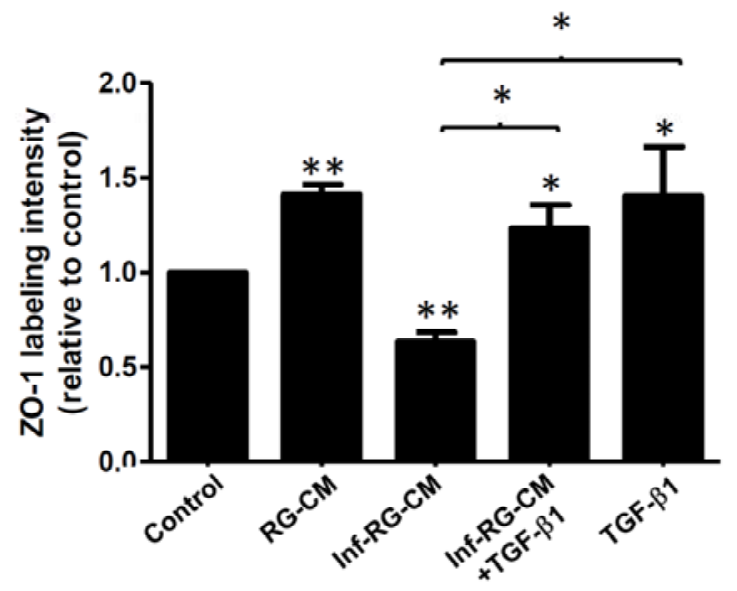




\section{Supplementary Figure 1.}

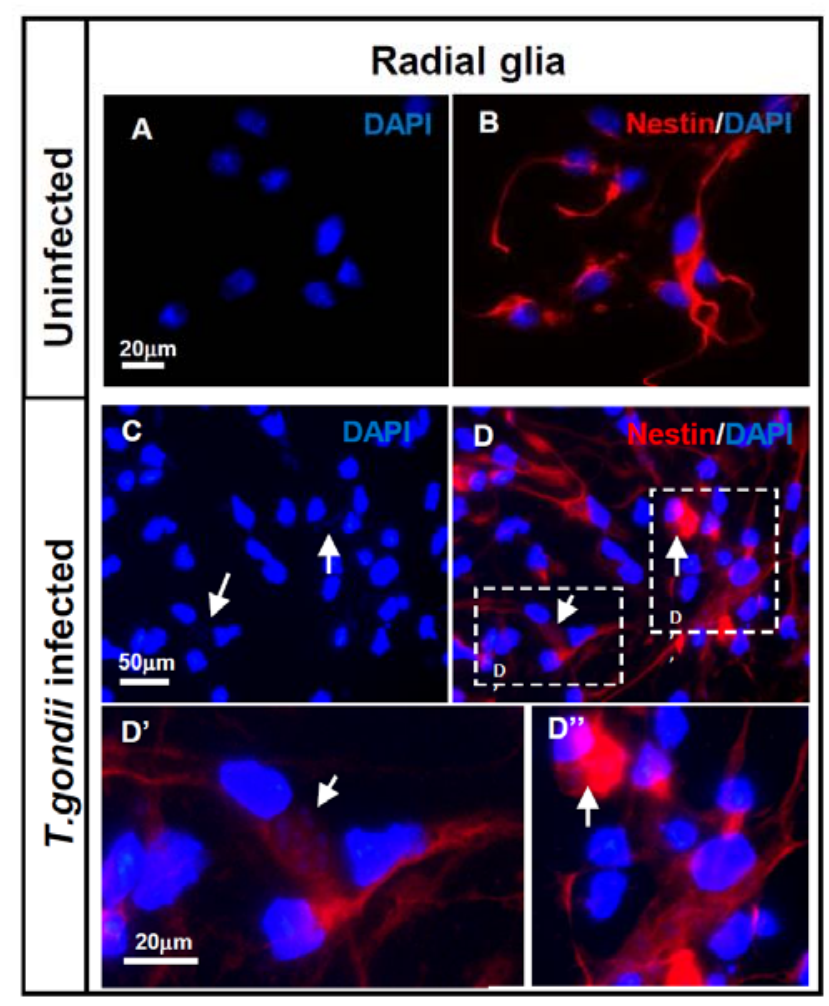




\section{Supplementary Figure 2.}
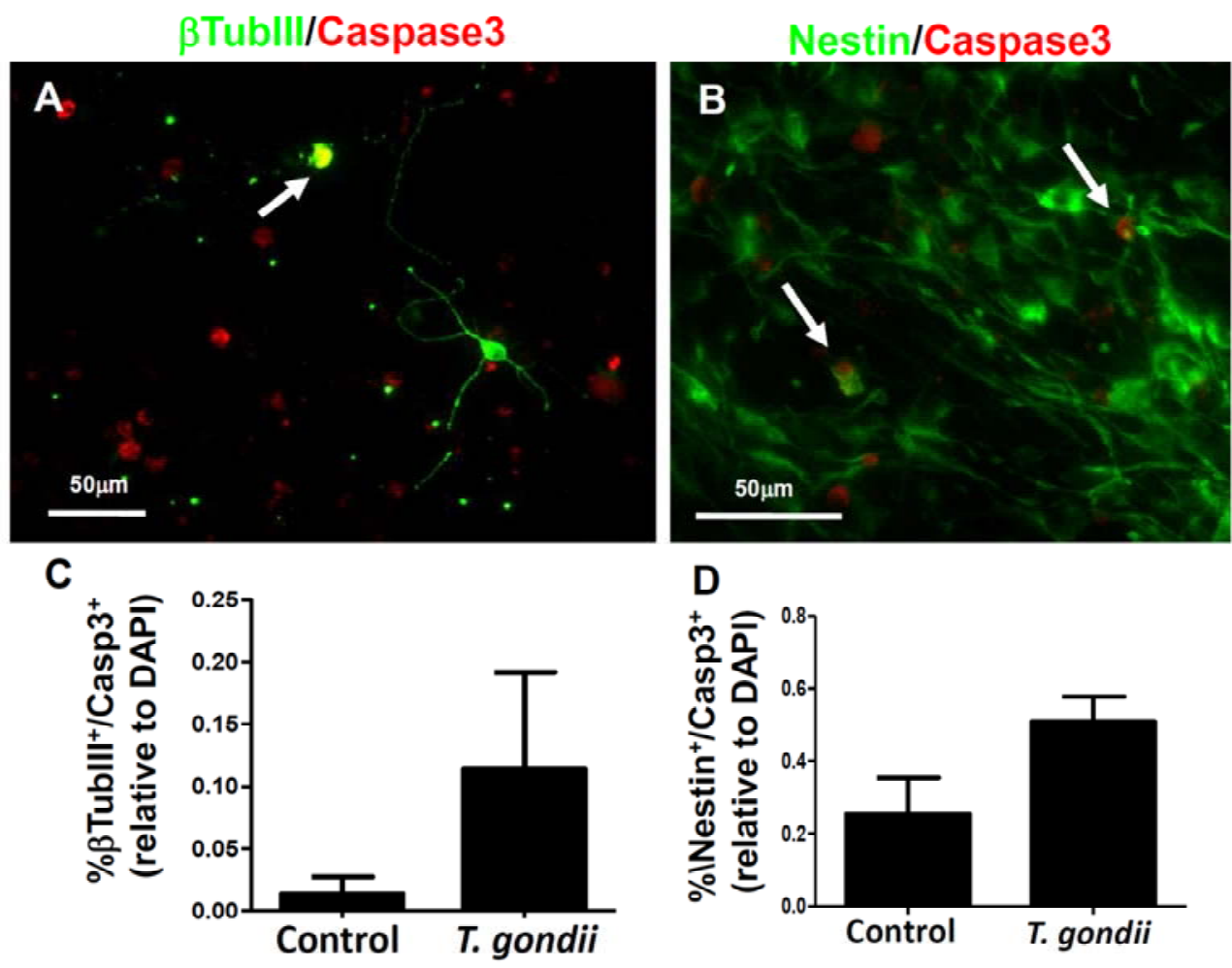

E

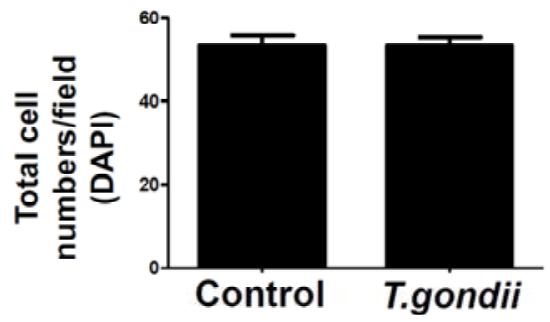



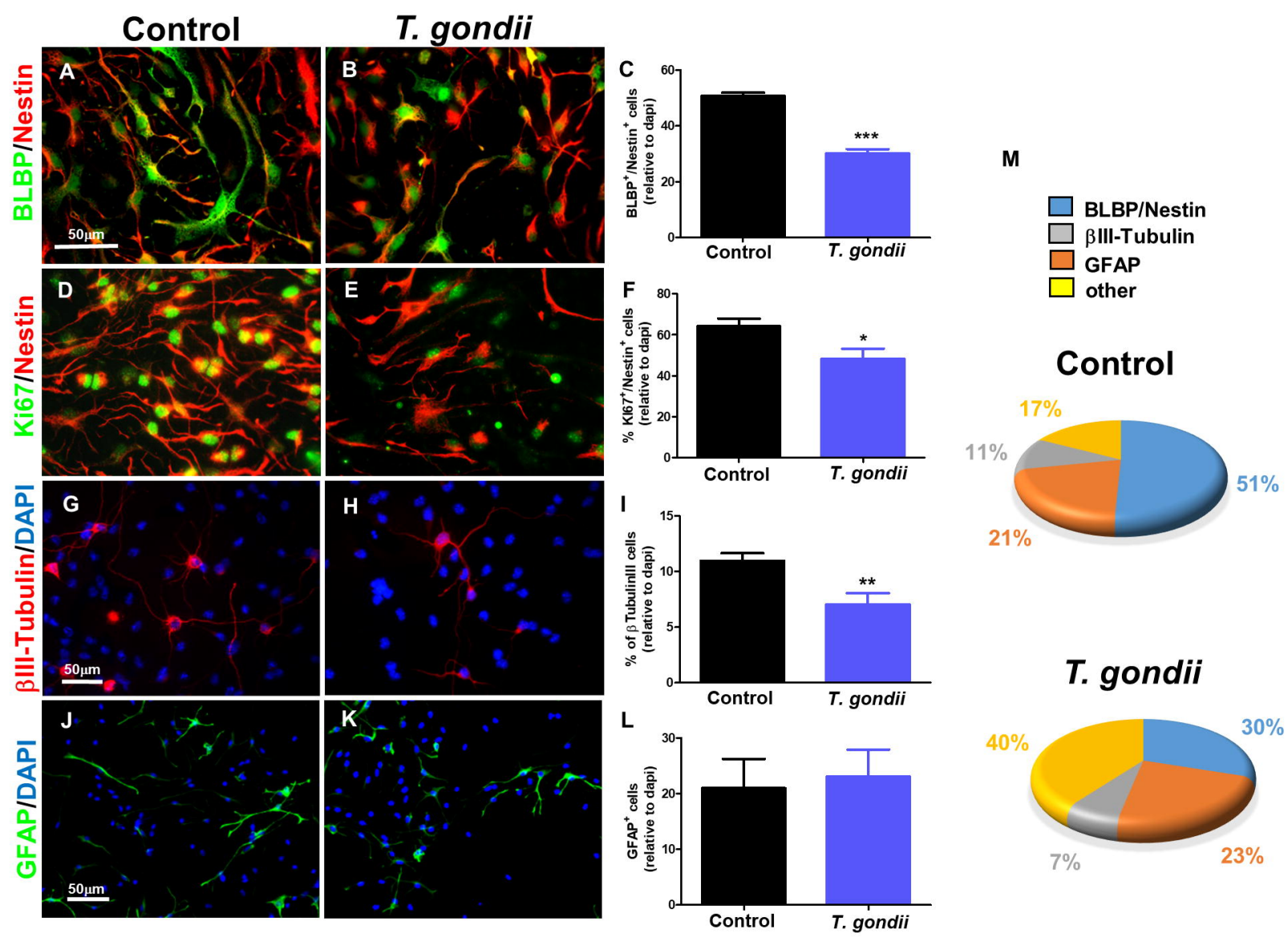

T. gondii

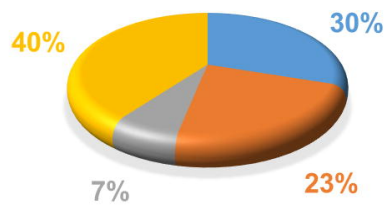




\section{Control}
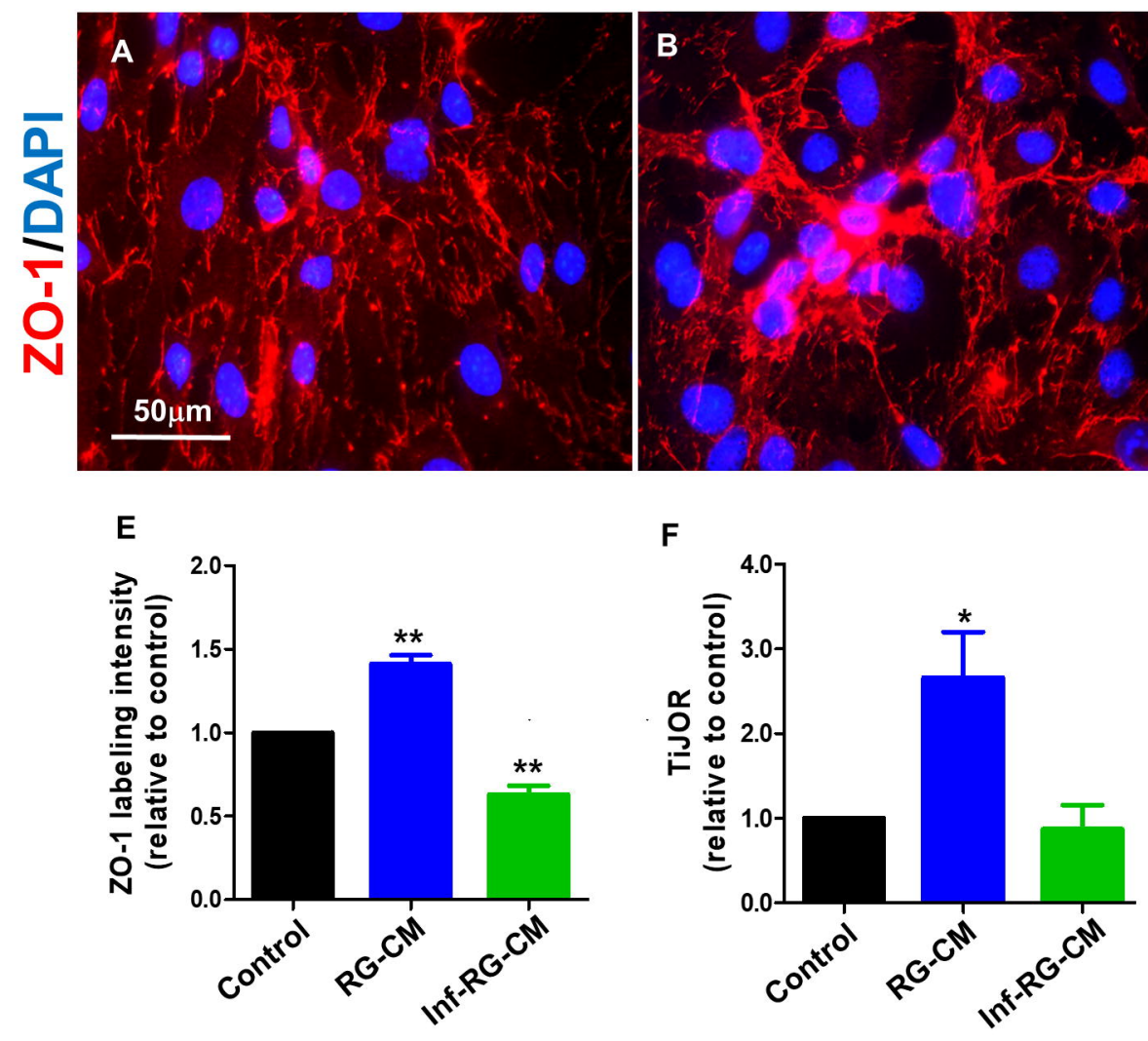

Inf-RG-CM

C

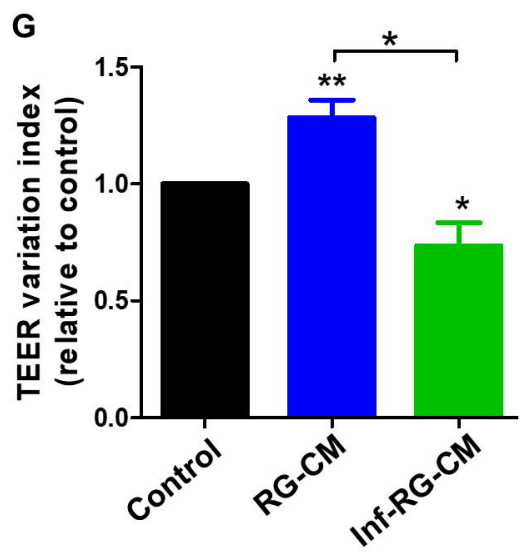

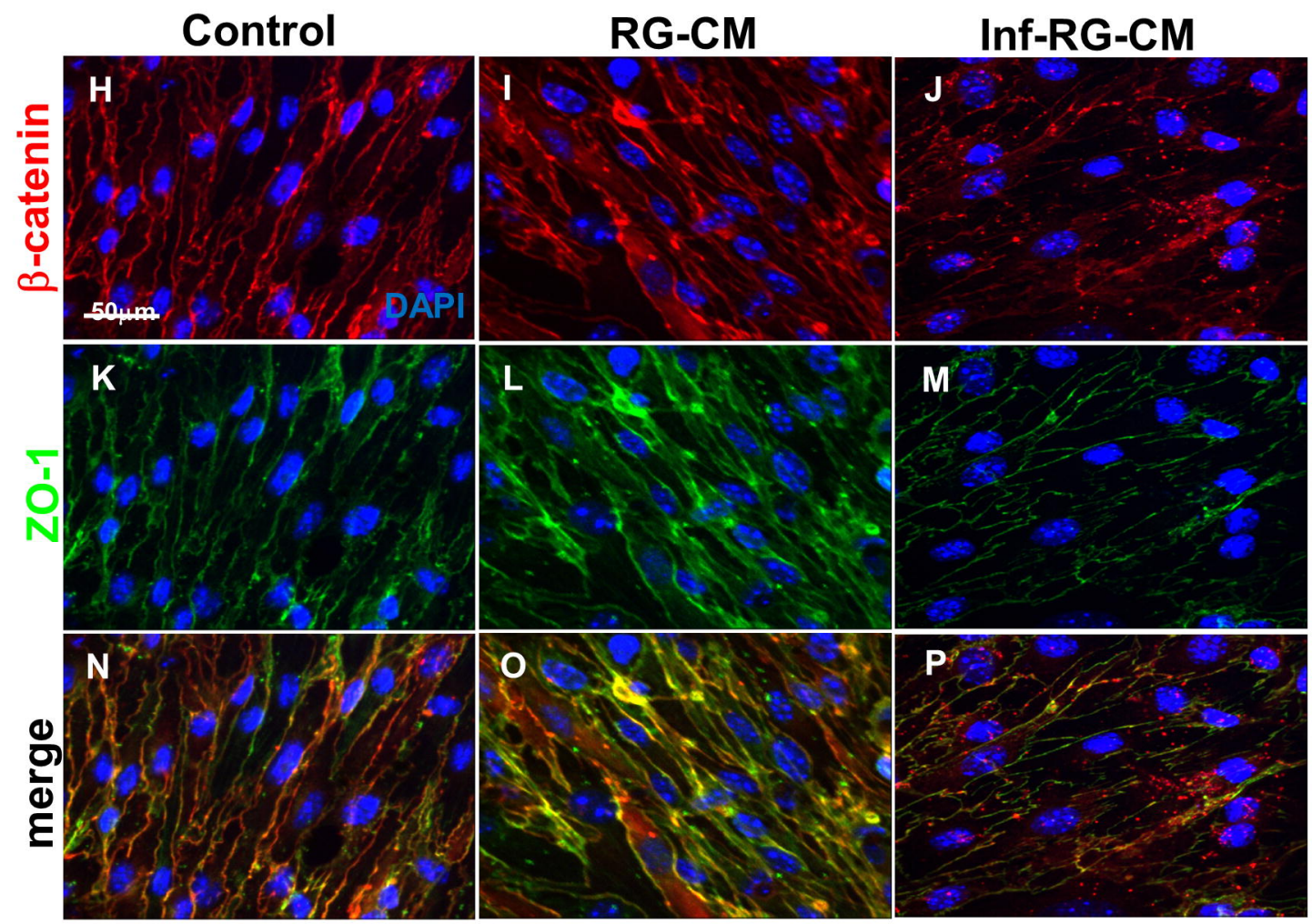




\begin{tabular}{|c|c|c|}
\hline \multicolumn{3}{|c|}{ Cytokine levels $(\mathrm{pg} / \mathrm{mL})$} \\
\hline & Control & T. gondii \\
\hline IL-2 & - & - \\
\hline IL-4 & - & - \\
\hline IL-6 & 0,3 & 7,4 \\
\hline IL-10 & - & - \\
\hline IL-17 & - & - \\
\hline INF- $\gamma$ & - & - \\
\hline TGF- $\beta 1$ & 29,0 & 18,0 \\
\hline TNF- $\alpha$ & - & - \\
\hline
\end{tabular}

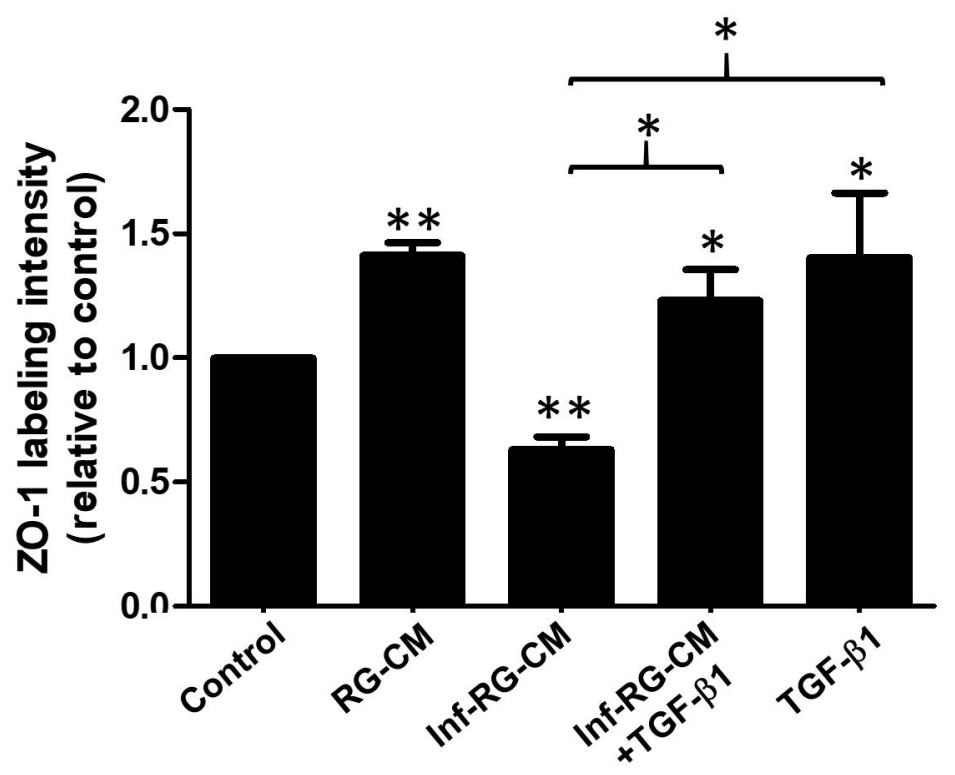

